\title{
Histiocytic sarcoma
}

Eduardo Silva Machado ${ }^{1}$

Ana Carolina de Miranda ${ }^{1}$

Ticiane Escopelli ${ }^{2}$

Ruggero Caron ${ }^{1}$

Alessandra Cristhina Escopelli ${ }^{3}$

'Universidade do Oeste de Santa

Catarina, Joaçaba, SC, Brazil

${ }^{2}$ Pontifícia Universidade Católica,

Curitiba, PR, Brazil

${ }^{3}$ Hospital Governador Celso Ramos,

Florianópolis, SC, Brazil
Conflict-of-interest disclosure:

The authors declare no competing

financial interest

Submitted: 7/6/2010

Accepted: 11/10/2010

Corresponding author:

Eduardo Silva Machado

ONCOESTE

Av. Santa Teresinha, 243/Sala 06 - Centro

89600-000 - Joaçaba, SC, Brazil

Phone: $55493522-5080$

ed.mach@terra.com.br

www.rbhh.org or www.scielo.br/rbhh

DOI: $10.5581 / 1516-8484.20110038$
A 59-year-old white woman, SC, after being treated for pneumonia, presented with an increase in the size of lymph nodes. The immunohistochemical examination diagnosed histiocytic sarcoma. Relapse occurred 12 months after starting chemotherapy. The patient evolved with febrile neutropenia, septic shock and death.

Keywords: Histiocytic sarcoma/diagnosis; Neoplasms; Case report

\section{Introduction}

Histiocytic sarcoma (HS) is a rare neoplasia ${ }^{(1-7)}$ of hematopoietic origin characterized by the proliferation of malignant cells that have the morphological and immunohistochemical characteristics of mature tissue histiocytes. ${ }^{(1,3)}$

Of unknown etiology ${ }^{(2,8,9)}$ and with a rapidly progressive clinical course, ${ }^{(2,8)} \mathrm{HS}$ represents less than $1 \%$ of all malignancies of the hematopoietic system. ${ }^{(10)}$ It mainly affects men and women (mean age of 46 years) ${ }^{(1,2,5,7,8)}$ but without differences between genders. ${ }^{(10)}$ In most cases, the presentation is extranodal, involving the skin, spleen and the gastrointestinal tract..$(4,8,11)$

Its presentation includes nonspecific systemic symptoms (fever, weight loss, anorexia, asthenia), hepatosplenomegaly, lymphadenopathy, intestinal obstruction, rash and pancytopenia. ${ }^{(2)}$

The definitive diagnosis of the disease is by an anatopathological study of one of the affected organ: bone marrow biopsy, an immunophenotypical study and genetic studies. ${ }^{(1,5,7,8)}$

HS is an aggressive neoplasia managed using different types of treatment including surgery, radiotherapy, chemotherapy and combinations thereof, depending on the stage of the disease..$^{(7,8)}$

The differential morphological diagnosis of histiocytic sarcoma includes inflammatory pseudotumor, follicular dendritic cell sarcoma, interdigitating dendritic cell sarcoma, malignant Langerhans' cell histiocytosis, large cell anaplastic lymphoma, melanoma and other sarcomas. ${ }^{(10,12)}$ The prognosis of histiocytic sarcoma is poor. The stage of the disease and, possibly, the tumor size are important prognostic indicators..$^{(1,3)}$

The aim of this report is to show the clinical and immunophenotypic characteristics of a case of HS and discuss about its treatment.

\section{Case report}

A 59-year-old white woman, SC, after being treated for pneumonia, returned to the doctor in January 2008, when he detected, at physical examination, a painless, fibroelastic lymph node of approximately $40 \mathrm{~mm}$ in the left cervical region. A biopsy was made after complete excision and a computed tomography $(\mathrm{CT})$ was requested. The $\mathrm{CT}$ demonstrated mediastinal and retroperitoneal lymphadenopathy and calcified granuloma in the right lower lobe of the lung. The biopsy initially was performed using the immunoperoxidase technique and the PicTure MAXTM Polymer method; the results were suggestive of non-Hodgkin lymphoma. The material was analyzed in the Consulting Pathology Service of Botucatu, São Paulo with the results of an immunohistochemical study defining atypical histiocytic proliferation. Eventually a sample was sent to Washington, USA where morphological and immunohistochemical alterations compatible with histiocytic sarcoma were identified: large cells with irregular-shaped nuclei and nucleoli, showing some binucleate forms and eosinophilic cytoplasm; positive immunophenotype for the CD68, CD163 and CD4 antigens which establish histiocytic proliferation and negative for CD1a 
and Langerin, which exclude the differential diagnosis of giant cell lymphoma and dendritic cell sarcoma. (Figures $1 \& 2)$.

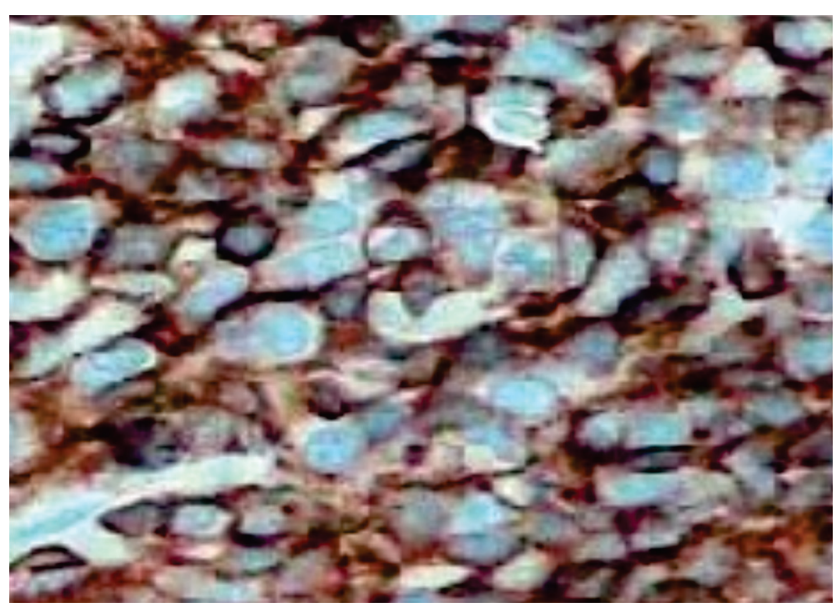

Figure 1- Immunohistochemical study proved to be positive for CD68. Immunophenotyping confirms the histiocytic lineage through an overexpression of the CD68 antigen

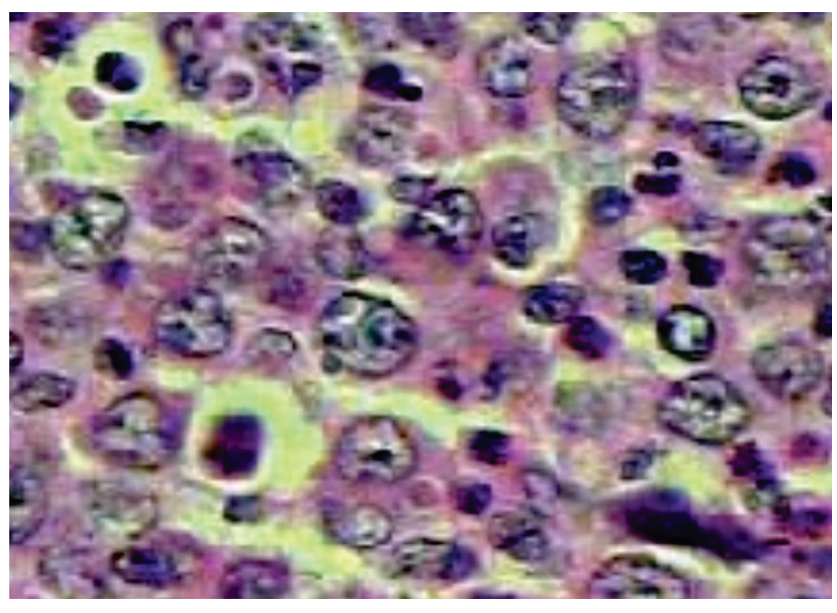

Figure 2 - Immunohistochemical study showing atypical histiocytic proliferation, diffuse proliferation of large cells with irregular nuclei, conspicuous nucleoli and abundant cytoplasm

In May 2008, the patient was referred to the oncology department of the Hospital Universitário Santa Terezinha (HUST). She was submitted to systemic staging with CT scans and laboratory tests which showed the following: enlarged retroperitoneal lymph nodes, measuring approximately $8 \mathrm{~cm}$; some enlarged mediastinal, paratracheal, para-aortic, aortopulmonary window and subcarinal pulmonary lymph nodes, and a residual granuloma of $8 \mathrm{~mm}$ in the lower right lobe of the lung; $\mathrm{Hb}: 12.2 \mathrm{~g} / \mathrm{dL}$ (11.5-16.5 g/dL); leukocytes: $5.8 \times 10^{6} / \mathrm{L}\left(4.0-11.0 \times 10^{6} / \mathrm{L}\right)$; platelets: $175 \times 10^{9} / \mathrm{L}(150-400 \times$ $\left.10^{9} / \mathrm{L}\right) ; 32$ macroglobulin: $1.85 \mathrm{mg} / \mathrm{L}(1.2-2.4 \mathrm{mg} / \mathrm{L})$; and LDH: 307.0 (88-230 units/L). Thus, chemotherapy with cyclophosphamide, doxorubicin, vincristine and prednisone
(CHOP) was indicated and started in June with a total of eight cycles completed in November.

After two months, the patient returned for evaluation in the oncology department, asymptomatic, but at physical examination two lymph nodes smaller than $10 \mathrm{~mm}$ (left supraclavicular/cervical region) were detected. They had a fibroelastic consistency and were not adhered to surrounding structures. CT scans were performed that gave normal results and laboratory tests showed no significant alterations. Expectant management was chosen and the patient was requested to return after approximately five months.

On her return in May 2009, the left supraclavicular lymph nodes were enlarged; the largest was $40 \mathrm{~mm}$ and both were painless and fibroelastic. Radiologic studies showed: enlarged retroperitoneal retrocaval lymph nodes, the largest measuring 40 by $20 \mathrm{~mm}$ and some lymph nodes measuring $15 \mathrm{~mm}$ along the ascending aorta.

After 30 days, the patient remained asymptomatic. A physical examination revealed enlarged mobile and hard lymph nodes in the left anterior cervical/supraclavicular region. Another analysis of a cervical lymph node was performed with the following result: lymph node diffusely altered by neoplastic malignancy suggestive of histiocytic sarcoma. CT scans showed enlarged retroperitoneal retrocaval lymph nodes with the largest measuring 35 by $30 \mathrm{~mm}$ and some lymph nodes measuring $10-15 \mathrm{~mm}$ along the ascending aorta. Laboratory tests showed no significant alterations. Salvage chemotherapy using etoposide, cisplatin, cytarabine and methylprednisolone (ESHAP) was begun on October, 7, 2009 with a planned $4-6$ cycles.

In spite of the patient having shown good initial clinical response, after being submitted to two cycles of chemotherapy, she evolved with febrile neutropenia triggered by an urinary tract infection. She was hospitalized for treatment with systemic antibiotic therapy. Even so, the patient evolved with hemodynamic instability and was transferred to the ICU where she died due to septic shock and multiple organ failure in December 2009.

\section{Discussion}

Clinically, these tumors, which in most cases occur in adults, show distinct presentations such as nonspecific systemic symptoms, hepatosplenomegaly, adenopathy and skin lesions. ${ }^{(3)}$ This case presented an asymptomatic clinical history throughout the clinical course of disease; an investigation of the case began due to the enlargement of a cervical lymph node.

The definitive diagnosis of the disease is reached by an anatomopathological test of affected organs with immunophenotypical and genetic studies. ${ }^{(1,3,7)}$

Lymph nodes affected by histiocytic sarcoma may show partial or complete effacement by a histiocytic proliferation of malignant cells. The degree of mitotic activity, closely parallel to the degree of cellular pleomorphism, is quite 
variable. Malignant cells have a large, eccentrically-placed, oval nucleus with vesicular chromatin and a prominent single irregular nucleolus. The cytoplasm is abundant and eosinophilic, and may be foamy or vacuolated. Large multinucleated cells and multiple nucleoli are also seen. The cytology of the tumor and architecture is not original and, therefore, immunophenotyping and molecular studies are absolutely essential for the diagnosis. ${ }^{(10)}$

Immunophenotyping confirms the histiocytic lineage by positive expressions of the macrophage associated antigens, CD68 and lysozyme, and negative for CD1a, CD21 and CD35. Recently characterized, the CD163 is a promising marker for histiocytic neoplasms. ${ }^{(9)}$

In this case, the diagnosis of HS was established by an immunophenotypical study with markers similar to those found in the literature. The anatomopathological study identified large cells with irregular shapes of the nucleus and nucleolus, some showing binucleate forms and eosinophilic cytoplasm, which were positive for the CD68, CD163 and CD4 antigens, thereby proving histiocytic proliferation. Additionally, the results were negative for CD1a and Langerin, which excludes the differential diagnoses of giant cell lymphoma and dendritic cell sarcoma.

HS is an aggressive neoplasia managed using different types of treatment including surgery, radiotherapy, chemotherapy and combinations thereof, depending on the stage of the disease. ${ }^{(7,8)}$ The treatment option in this case was systemic chemotherapy because the diagnosis was delayed and the patient already had involvement of several lymph nodes (cervical, mediastinal and retroperitoneal) thus confirming the advanced stage of disease.

Considering the poor prognosis in this disease associated with great systemic involvement, the patient progressed to death due to complications of treatment.

This is a disease with poorly defined characteristics like most lymphoproliferative disorders; diagnosis must be guided by the interpretive findings of an immunophenotypical study.

\section{References}

1. Alexiev BA, Sailey CJ, McClure SA, Ord RA, Zhao X, Papadimitriou JC. Primary histiocytic sarcoma arising in the head and neck with predominant spindle cell component. Diagn Pathol. 2007; $2: 1-7$.

2. Khosravi SP, del Castillo RA. Sarcoma histiocítico: caso clínico y revisión de la literatura. An Med Interna. 2005;22(4):185-7.

3. Kobayashi S, Kimura F, Hama Y, Ogura K, Torikai H, Kobayashi A, et al. Histiocytic sarcoma of the spleen: case report of asymptomatic onset of thrombocytopenia and complex imaging features. Int J Hematol. 2008;87(1):83-7.

4. Oka K, Nakamine H, Maeda K, Yamakawa M, Imai H, Tada K, et al. Primary histiocytic sarcoma of the spleen associated with hemophagocytosis. Int J Hematol. 2008;87(4):405-9.

5. Schnettler K, Salomone C, Valbuena J R. Sarcoma histiocíticocutáneo: Reporte de un caso. Rev Med Chil. 2009;137(4):54751 .

6. Vos JA, Abbondanzo SL, Barekman CL, Andriko JW, Miettinen M, Aguilera NS. Histiocytic sarcoma: a study of five cases including the histiocyte marker CD163. Mod Pathol. 2005;8 (5):693-704.

7. De Vos FY, Gerding MN, Arends JW, Wegman JJ. Histiocytic sarcoma localised in the thyroid - a case report. Ann Hematol. 2008;87(8):681-2.

8. Avilés-Salas A, Peña-Torres ML, Molina-Cruz A, Rivas-Vera S. Sarcoma histiocítico de intestino delgado: reporte de un caso y revisión de la literatura. Rev Med Chile. 2009;137(2):269-74.

9. Noguchi DT, Guimarães FP, Alves MT, Lee M, Cypriano M, Chan J, et al. Sarcoma histiocítico: Relato de caso em uma criança de 16 meses. [Abstract]. Available from: http://www. oncopediatria. org.br/oncologistas?page $=6$

10. Khosravi Shahi P, del Castillo Rueda A. Sarcoma histiocítico: caso clínico y revisión de la literatura. An Med Interna (Madrid) [Internet]. 2005;22(4):35-7. Available from: http://scielo.isciii.es/ pdf/ami/v22n4/nota2.pdf

11. Yaman, E, Ozturk B, Erdem O,Gokcora N, Coskun U, Uluoglu O, et al. Histiocytic sarcoma: PET-CT evolution of a rare entity. Ann Nucl Med. 2008;22(8):715-7.

12. Lillo NC, Sastre ER, Uriach AP, Cósio-Piqueras MG, Roldan AS, Beiras A, et al. Sarcoma histiocítico con rasgos inmunohistoquímicos y ultraestructurales de células dendríticas interdigitantes. Rev Esp Patol. 2008;41(3):237-41. 